\title{
Optimization of orthodontic treatment using the Centrex System to retract anterior teeth
}

José Kleber Soares de Meireles', Weber Ursi²

Introduction: In the end of 90's the adoption of mini-implants as Anchorage allowed a paradigm change influencing even the way of thinking orthodontic mechanics. The overlapping of the specialties of Orthodontics and Implantology started with orthodontic preparations for prosthetic implants insertion, aroused with the use of palatal implants and late with the introduction of mini-implants. The improvement of mini-implants insertion technique with the appearing of self-drilling screws has allowed orthodontists to plan and to place this precious Anchorage piece. Taking into account the versatility of positioning of these screws it was developed a concept that allows the construction of force action lines aiming at optimize the planning and predictability of orthodontic motion.

Objective: To present some clinical results treatments conduct using Centrex System of orthodontic treatment, approximating the force line action of resistance center of units to be moved. The traced way to its development, previously treated in this journal, will be detailed for better understanding of its functioning.

Keywords: Orthodontic anchorage. Dental mini implants. Center of resistance.

» Patients displayed in this article previously approved the use of their facial and intraoral photographs.

${ }^{1}$ Specialist in Orthodontics, PROFIS-USP. Professor of Orthodontics, ABO-Bahia.

${ }^{2}$ Full Professor, UNESP.

\author{
How to cite this article: Meireles JKS, Ursi W. Optimization of orthodontic treat- \\ ment using the Centrex System to retract anterior teeth. Dental Press J Orthod. 2012 \\ July-Aug;17(4):29-44. \\ Submitted: September 15, 2008 - Revised and accepted: March 09, 2009 \\ » The authors report no commercial, proprietary or financial interest in the products \\ or companies described in this article. \\ Contact address: José Kleber Soares de Meireles \\ Av. ACM, 585 - Sala 504 - Bairro Itaigara - CEP: 41825-000 \\ Salvador/BA - Brazil - E-mail: jksm@uol.com.br
} ver/BA-Brazil-E-mail: jksm@ulcom.br 


\section{Otimização do tratamento ortodôntico utilizando o Centrex System para retração dos dentes anteriores}

José Kleber Soares de Meireles', Weber Ursi²

Introdução: a Ortodontia passa, atualmente, por um momento de importantes inovações e grande efervescência criativa. Somente para citar algumas mudanças introduzidas ou aprimoradas nos últimos anos, nós podemos relembrar a "popularização" dos braquetes autoligáveis e o surgimento da ancoragem absoluta com a utilização de implantes ortodônticos. No final da década de 1990, a adoção dos mini-implantes como ancoragem permitiu uma mudança de paradigma que tem influenciado até mesmo a forma de pensar a mecânica ortodôntica. A imbricação das especialidades de Ortodontia e Implantodontia, cujo início se deu com os preparos ortodônticos para posterior inserção de implantes protéticos, floresceu com o uso de implantes palatinos e, posteriormente, com a introdução de mini-implantes. O aprimoramento da técnica de inserção de mini-implantes com a introdução de parafusos autoperfurantes tem permitido, inclusive, o requinte do ortodontista concentrar em suas mãos o planejamento e a colocação dessa preciosa peça de ancoragem. Levando em consideração a versatilidade de posicionamento desses pequenos parafusos, foi desenvolvido um conceito que possibilita a construção de linhas de ação de força que buscam otimizar o planejamento e a previsibilidade da movimentação ortodôntica.

Objetivo: apresentar alguns resultados clínicos de tratamentos conduzidos com o uso de um sistema de tratamento ortodôntico, o Centrex System, que aproxima a linha de ação da força do centro de resistência das unidades a serem movimentadas. $\mathrm{O}$ caminho trilhado até o seu desenvolvimento, cuja teoria mecânica foi apresentada anteriormente nesse periódico, será detalhado para uma melhor compreensão de seu funcionamento.

Palavras-chave: Ancoragem ortodôntica. Mini-implantes. Centro de resistência.

» Os pacientes que aparecem no presente artigo autorizaram previamente a publicação de suas fotografias faciais e intrabucais.

${ }^{1}$ Especialista em Ortodontia, PROFIS - USP. Professor dos cursos de Aperfeiçoamento e Especialização em Ortodontia, ABO-Bahia.

${ }^{2}$ Professor Livre Docente, UNESP.
Como citar este artigo: Meireles JKS, Ursi W. Optimization of orthodontic treatment using the Centrex System to retract anterior teeth. Dental Press J Orthod. 2012 July-Aug;17(4):29-44.

Enviado em: 15 de setembro de 2008 - Revisado e aceito: 09 de março de 2009

» Os autores declaram não ter interesses associativos, comerciais, de propriedade ou financeiros, que representem conflito de interesse nos produtos e companhias descritos nesse artigo.

Endereço para correspondência: José Kleber Soares de Meireles Av. ACM, 585 - Sala 504 - Bairro Itaigara - CEP: 41825-000 Salvador/BA - E-mail: jksm@uol.com.br 


\section{INTRODUCTION}

The use of prosthetic implants in orthodontic planning requires from Implantology and Orthodontic professionals a varied knowledge. As in cases that are referred by implantodontists for an orthodontic preparation prior implants placement, as in cases referred by orthodontists for the insertion of osseointegrated implants that will work as anchorage, a great interaction is demanded between professionals involved, as well as a minimal knowledge of the resources of another specialty, at least enough to discuss the needs and possibilities involved in the case. In the first case, the mastery of orthodontic set up preparation allows the correct planning of implant positioning without the risk of making these implants prevent posterior tooth movement. In the second case, the implant type choice, the region to receive the implant, the healing period prior to the application of orthodontic force and the magnitude of that force, they are all information that should be shared between the two specialties.

In the case of implants used only for anchorage, the location choice, size and even the type of head of the implant are defined by the orthodontist. These are always orthodontic options, since they are directly and inseparably linked to the treatment planning and to the chosen mechanics. Thus, it is natural that the orthodontist keeps taking for himself the responsibility of placing mini-implants in his clinical practice. This transition has been occurring gradually.

When the first mini-implants were introduced to the medical armamentarium, initially with the palatal implants ${ }^{28}$ their application was almost restricted to the use of indirect orthodontic load, with a transpalatal arch connecting upper molars to the implant. That was beyond question an advance for a more efficient anchorage. Nevertheless, disadvantages as the flexibility of the arch, associated with the maintenance of traditional sliding mechanics for retraction, allowed some mesialization of posterior teeth, besides not correcting the concepts of force application, which was kept away from the center of resistance of units to be moved.

The inclusion of versatile mini-implants $(\mathrm{MI})^{12}$ to the clinical practice allowed great and positive changes in orthodontic protocols. In the yet very recent early years of the use of these implants, possibly because the planning and insertion were performed almost exclusively by implantodontists, the placement of these small anchorage parts had high periodontal indications. Buccally inserted implants in cases of anterior teeth retraction, for example, were almost always situated in a position close to the clinical crown, always aiming to be placed in attached gingiva. Such placement, almost unalterable, required orthodontic mechanics to stay overpowered to the position of MI. It was the time of ascendency of implantology over mechanics. As the quantity and quality of inserted gingiva can vary considerably between individuals and mouth regions, in some cases reaching less than $1 \mathrm{~mm},{ }^{26}$ this could impose one more challenge for MI insertion and for orthodontic practice. The implant improvement and surgical technique have lead to what we consider more correct: The MI positioning as part of orthodontic planning, aiming at mechanical optimization. This is a new path that literature has trailed ${ }^{27}$ and has produced important changes in the way to conduct biomechanics in Orthodontics.

In a previous article ${ }^{19}$ a proposal of orthodontic movement was presented with appliances capable of moving apically the force action line to the desired position, according to previous planning. In this paper clinical applications of these concepts discussed before will be presented. Cases involving anterior teeth retraction, will be emphasized, one of most frequent clinical situations in orthodontic practice.

\section{Anterior teeth retraction}

Upper anterior retraction (UAR) or lower (LAR) is one of most difficult clinical steps for the orthodontist, specially for the fact that it in itself some traps that, in grater or smaller magnitudes, can harm the treatment process or even make its continuation unfeasible due to an eventual excessive loss of root structure. Such occurrence is more common in upper and lower incisors during distal movement of these teeth for Class II correction or double protrusions. ${ }^{24}$ The lack of adequate torque control during UAR tends to produce an out of control inclination movement of anterior teeth, buccally protruding the apical third of these teeth in an area of low osseous availability (Fig 1). ${ }^{19}$ This becomes even more relevant in cases of adult patients with horizontal bone loss, since the applied force in the crown is transferred to the apices with greater magnitude, since the center of resistance of teeth, in such situations, are more apically located. 
Greater force magnitude, apart from unwanted, increases apical root resorption in these teeth., ${ }^{7,17}$

Eventually if loss of inclination control occurs during retraction, in addition to the possibility of root resorption there is a tendency of excessive uprighting of the anterior teeth. Such a fact is perceived mainly, in cases of great retractions. What happens is that the force, being applied at the crown of the teeth, produces a movement of great magnitude that is greater the more apical positioned is the center of resistance of the teeth set being distalized. In view of that, such teeth tend to rotate clockwise. The excessive uprighting of these units also can result in an increase in overbite. ${ }^{2}$

It is not uncommon to observe in treatment planning involving upper teeth extractions for overjet correction, the blocking of distal movement of anterior teeth, due to the absence of horizontal overlap, without, however, obtaining the correction of canine relation. What is seen in these cases is a situation like the one described in Figure 2.

This loss of inclination control besides blocking UAR tends to project the apex of the anterior teeth over the maxillary buccal cortex, in this way increasing the resorption potential of these teeth..$^{2,24}$

Figure 3 images show the difficulties usually found in overjet correction. Anterior teeth inclination in the beginning of treatment was slightly increased, however retraction magnitude, in this case assisted by indirect anchorage with the palatal implant, associated to the difficult torque control with polycarbonate brackets (even with metallic slots) made such teeth loose a lot of inclination until the end of treatment.

In order to avoid this effect, a strict anterior torque control is vital during UAR or LAR. The incorporation of active buccal torque or resistent torque should be planned to avoid such occurrence. Nevertheless, once this has happened, retraction mechanics should be interrupted until negative effects are corrected. At this point, it is necessary to include active palatal root torques to regain an adequate overjet to give continuity to the retraction movement of the anterior teeth (Fig 4). ${ }^{2}$

Although the reversion of the inconveniences previously mentioned is possible, there is a delay in treatment, creating an interruption point, where only the correction of errors incorporated during mechanics is corrected. It is common to think that the use of pre adjusted brackets can prevent the occurrence of these side effects. This is a huge mistake perpetuated by the idea that straight wire mechanics is simple and infallible. No mechanics or bracket have in themselves the solution for all orthodontic problems. It is important to have good sense and reasoning to know the moment to use different resources and techniques, always focusing in the best result for the patient.

As well stated by Capelozza et al: 6 "individualized treatment plan, individualized appliance and mechanics. Certainly this is to look at the future." The individualization of brackets for orthodontic movement
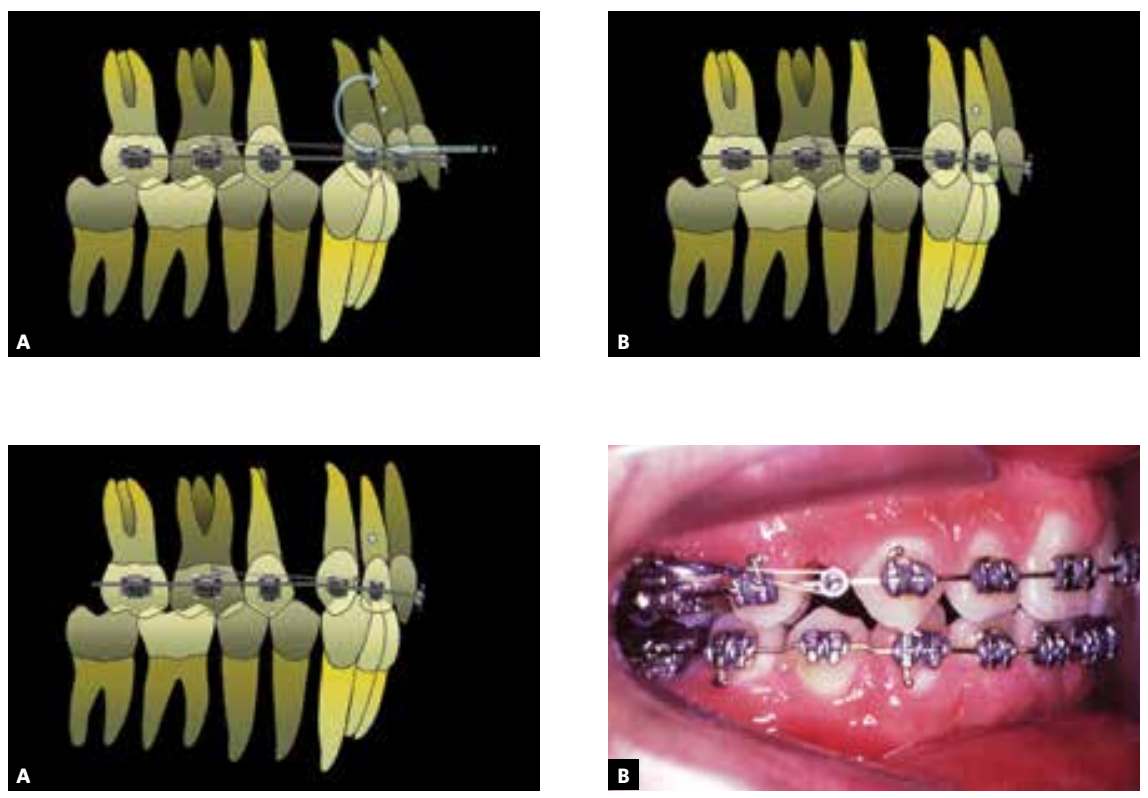

Figure 2 - The contact between upper and lower incisors occurred before the correction of canine relation $(\mathbf{A})$. A clinical example of this situation $(\mathbf{B})$. 

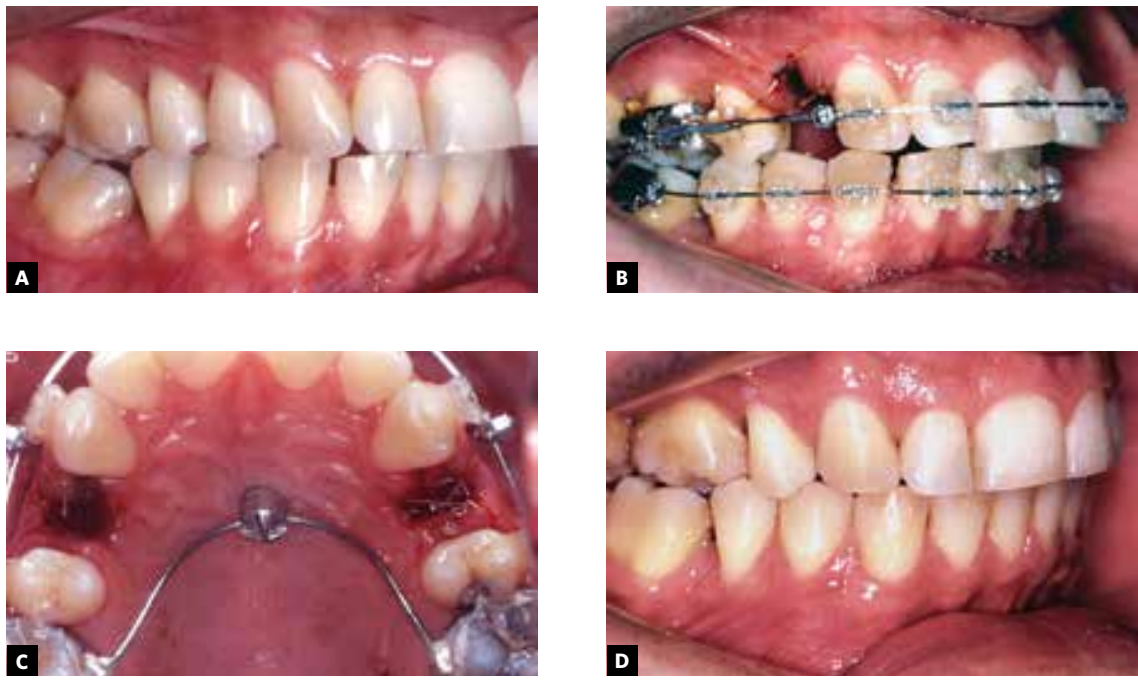

Figure 3 - Upper premolar extractions were planned for correction of increased overjet (A, B). A palatal implant was used and indirect anchorage transferring its rigidity to molars by the a transpalatal $\operatorname{arch}(\mathbf{C})$. At the end of retraction, anterior teeth lost much of their inclination (D).

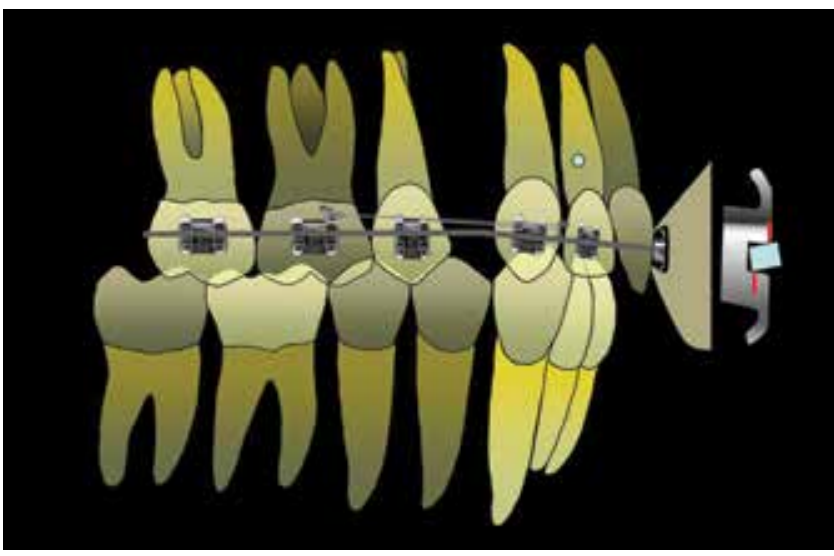

Figure 4 - Example of necessary torque for correction of upper incisors inclination. must be thought not only in the individual types of bracket, but also in the combination with the available wires. A good example of this philosophy is the following: let's think a certain upper central incisor bracket has an inclination prescription (torque) of $+12^{\circ}$. In the beginning of the retraction stage, if this inclination is considered appropriate and it is desired to keep it, the only way to perform it, using a wire without anterior torque, is to increase the wire caliber, approximating to the slot dimensions. In case of a slot measuring $0.022 \times 0.030$-in, the choice would be a $0.021 \times 0.025$-in wire. Filling the slot allows the full expression of the prescription, including torque, embedded in the bracket, besides the adequate inclination control during movement of the teeth. The problem is that this wire almost makes retraction by sliding impossible, since friction in the anterior region would be an impeditive factor for such tooth movement. ${ }^{3,13}$

On the other hand, if a $0.017 \times 0.025$-in wire were used, sliding would be easier. Nevertheless, such dimensions would not allow an ideal inclination control of anterior teeth, since there is a considerable 
gap between wire and slot. In this case, if the aim to maintain inclination, at least the incorporation of a resistant buccal crown torque is necessary. It would be interesting that the orthodontic supplies companies make available different wire calibers for anterior and posterior regions. However, this is not the solution for all problems, as the abundance of brackets available in the market is also not the solution. As an example, the introduction of a higher inclination in individualized brackets for anterior teeth when they are under retraction has become common. This procedure tries to compensate the loss of inclination caused by the use of a lower caliber wire, as if it were a resistent torque. ${ }^{2}$ Although correctly indicated in such situations, the use of this resource can generate excessive inclination of anterior teeth and ceased the distal movement of incisors, specially if a higher caliber wire is inserted.

Since the adequate inclination for anterior teeth is directly dependent on the facial pattern of each individual, the necessary compensation for treating Class II or III individuals is not constant, closely depending on the magnitude of the problem. Therefore, only the absolute individualization, with brackets made exclusively for each case, can grant the abolition of torque or adjustment needs in the wire-bracket management, what clearly is, at least nowadays in the Brazilian reality, commercially unfeasible. Hence, torque control by means of orthodontic wires is still necessary in any type of bracket, specially when the straight wire technique with sliding mechanics is used. In individuals presenting bone loss in the anterior region, torque control is even more critical, since the center of resistance of the teeth is further away from the crown, where the force is applied..$^{19}$ In these cases, torque magnitude should be increased to interpose the force generated by the retraction. In some situations, it is appropriate to modify the force line of action to make it closer to or even coincide, in height, to the center of resistance of teeth to be moved. ${ }^{1}$ This concept will be present in the clinical cases illustrated in this article.

The possibility of insertion of mini-implants in different positions allows a more favorable management of orthodontic mechanics. Some papers have suggested a more apical orthodontic force of retraction, in order to optimize mechanical results ${ }^{14,21}$ and the mechanics should be driven by this rationale.

The development of the Centrex System was based, among other factors, in the observation of side effects quoted in this paper. In order to give greater efficiency to the movement of the anterior teeth, first the stretching of the retraction hooks in the apical direction was tested, with the purpose of decreasing the moment acting on the set of incisors and canines. Nevertheless, there was yet the need to use smaller caliber wire to allow retraction with less friction. ${ }^{5}$ The use of the Centrex System was, as will be seen below, the next step in attempting to solve, or at least minimize, this and other disadvantages of the mechanics.

It is important to point out that some plans require the adoption of a force line of action closer to the crown of the teeth, as for example in cases of excessive inclination of anterior teeth, in which the introduction of a clockwise movement is welcome. Nevertheless, even in such cases, it should be borne in mind that at some point of the retraction, the positional control of the teeth will be necessary with the use of torque. ${ }^{18}$

The next cases exemplify situations in which the line of force was instituted in different heights and inclinations, describing the objectives and results of such choices.

\section{CLINICAL CASES}

\section{Case 1 (Figs 5 to 8)}

Female patient, 26 years old, had a Class II, right subdivision, dental relationship as a result of the early loss of tooth 46. Facial analysis made evident a Class I pattern with labial double protrusion, being that her main complaint. The proposed treatment plan was with three extractions: two first upper premolars and the first left lower premolar, to enable upper and lower anterior retraction with decrease of double protrusion. To do this, a very powerful anchorage would be necessary. Two MI were inserted to the upper and lower dental arch, in the left quadrant, all mesially positioned near the molars and dental crowns. The retraction with the line of force coronally positioned in relation to the center of resistance of six anterior teeth required the construction of resistant anterior torques throughout the movement, aiming for a suitable mechanical control during correction of inclination and protrusion of teeth. An intrusive component was present in the upper arch, during retraction, because of the inclination of the line of force, which helped, in this case, the vertical control during distalization of anterior teeth (Fig 5 to 8). 

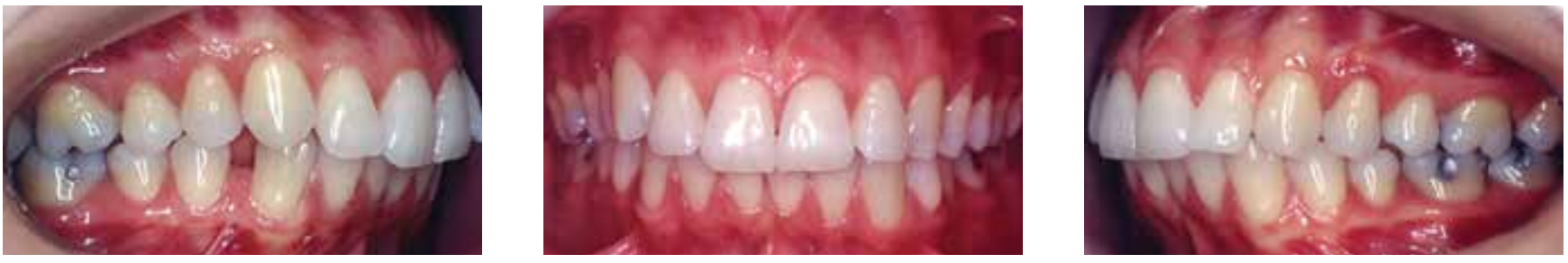

Figure 5 - Excessive anterior dental protrusion prints its mark with the exposure of well-defined root contours.
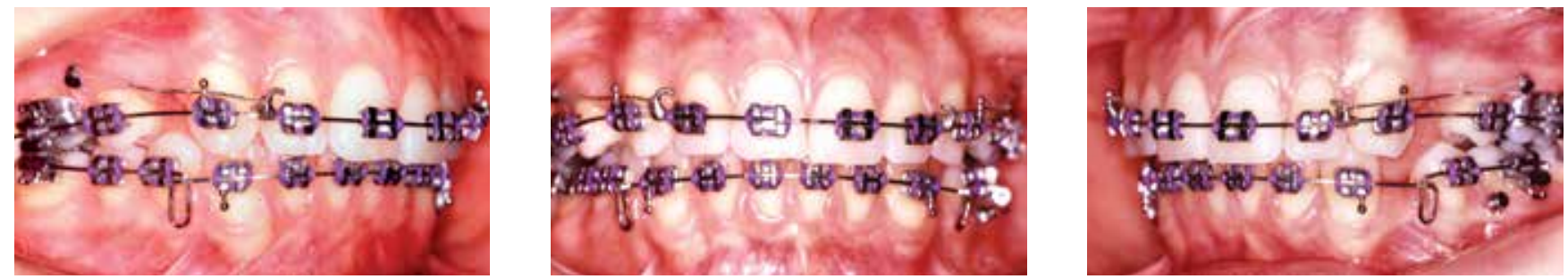

Figure 6 - Ml inserted next to crowns.
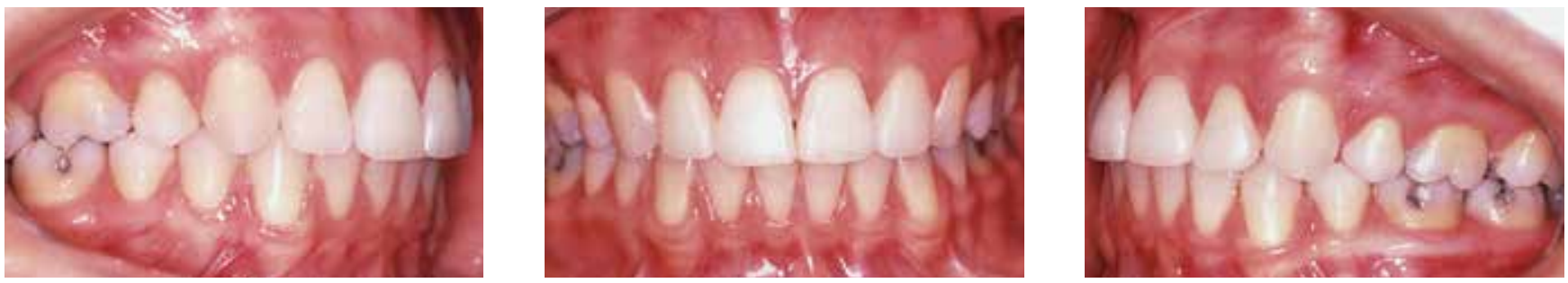

Figure 7 - End of treatment with inclination correction and the anterior protrusion.
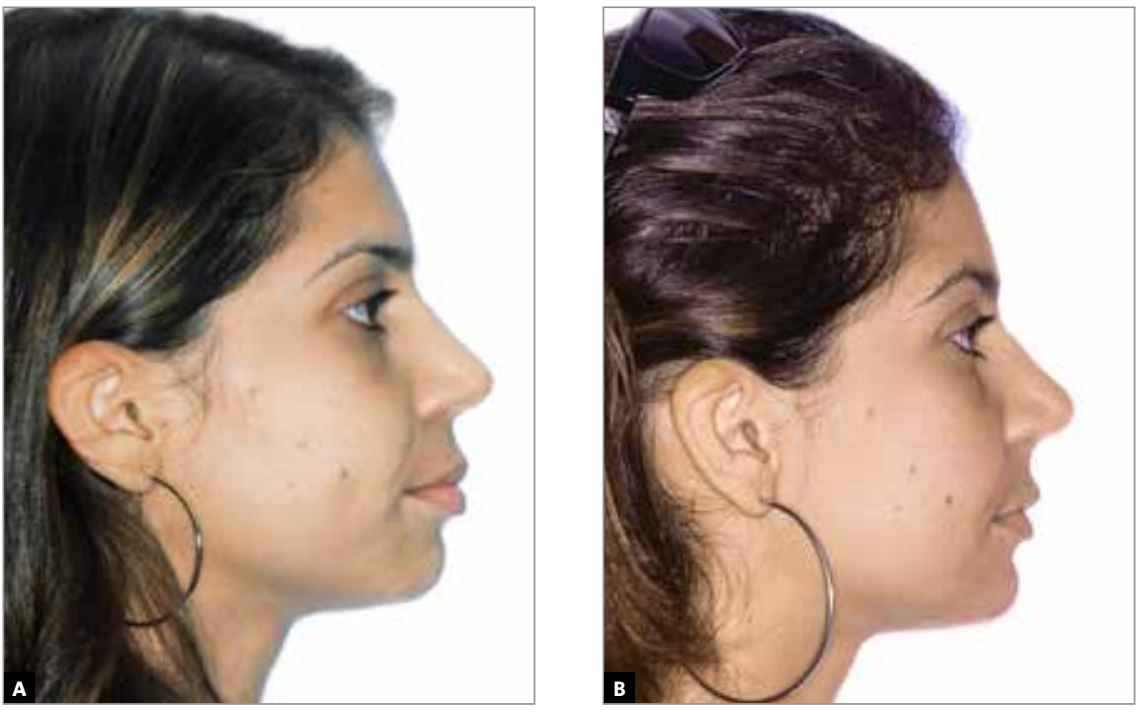

Figure 8 - Facial profile before (A) and after (B) orthodontic correction, highlighting the "smoothing" of lip filling post-treatment. 


\section{Case 2 (Figs 9 to 12)}

Female patient, 29 years old, was in treatment for approximately three years with another professional, when looked for a second opinion for resolution of increased overjet, which was being handled without extractions. The new treatment plan consisted in extractions of first two first upper premolars to provide space for the correction of the excessive overjet. Two MI were inserted bilaterally distal to the second upper premolars, at a height of $6 \mathrm{~mm}$ above the orthodontic wire, so, presumably, a little below the center of resistance of the six anterior teeth.
Such position endorsed the construction of a line of force that produced a clockwise moment of small magnitude, allowing the correction of the inclination of the upper teeth. The use of a wire with a smaller caliber than the slot at the beginning of the retraction, in this case a wire of $0.018 \times 0.025$-in, contributed to the correction of incisor inclination. When the upper anterior teeth reached its proper inclination, the wire was changed to a larger caliber (0.021 x 0.025-in). The end of the retraction was done with the CSl device, installed unilaterally in order to obtain the upper midline correction.
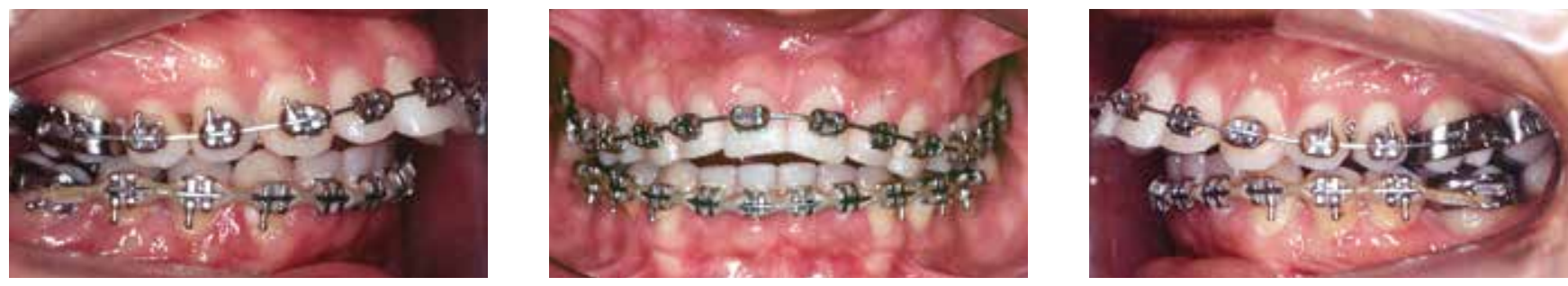

Figure 9 - The patient had, at the beginning of treatment, a Class II relation and very increased overjet.
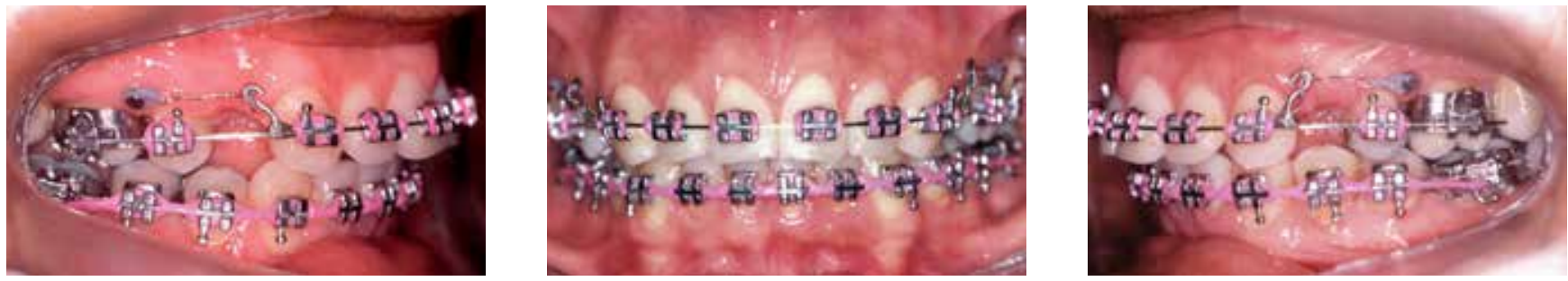

Figure 10 - Mini-implants insertion was made at approximately $6 \mathrm{~mm}$ in height and the hook was welded to the wire and extended apically to provide a horizontal line of action in relation to the occlusal plane, avoiding vertical effects.
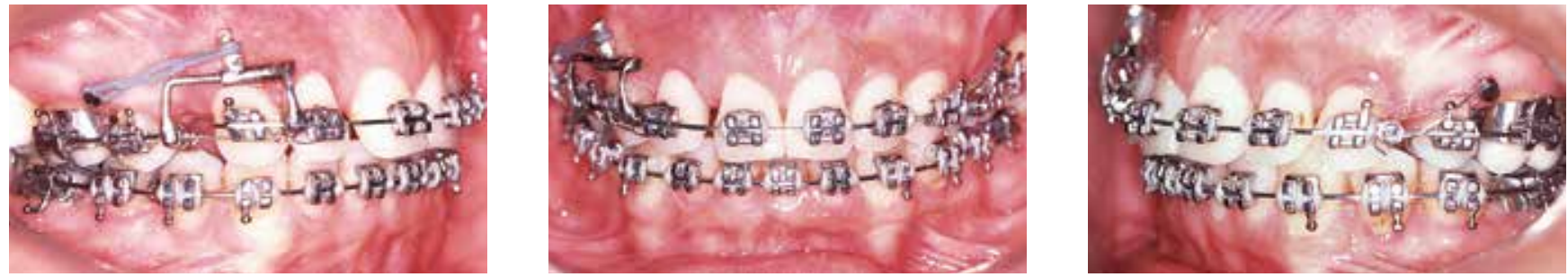

Figure 11 - The completion of correction of canine relationship on the right side. On the left a steel ligature wire was kept together to a gurin type device to prevent rotation of the rectangular wire.
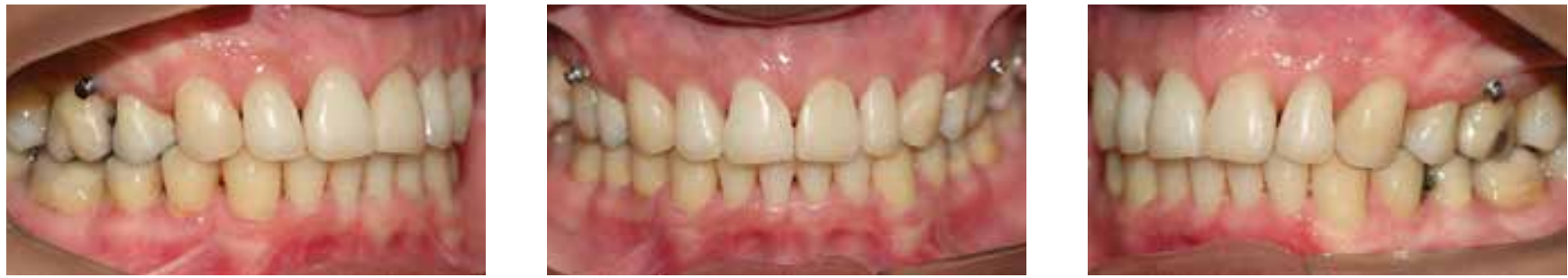

Figure 12 - End of treatment with correction of Class II and overjet. 


\section{Case 3 (Figs 13, 14, 15)}

Patient with 23 years of age, Class II, increased overjet and overbite, incisors excessively buccally inclined. The treatment plan included the insertion of mini-implants between molars and seconds upper premolars, at a height of approximately $7 \mathrm{~mm}$. Extractions of the upper first premolars for overjet correction was performed.

In upper anterior retraction stage, a $0.017 \times 0.025$ in stainless steel wire was inserted, in order to allow some loss of inclination of anterior teeth. At the end of 25 months of treatment, the upper incisors had a satisfactory inclination and the canines were in Class I.

\section{Retraction using Centrex System 1 (CS1)}

Orthodontic treatment with continuous arches, whether it's with pre-adjusted or standard brackets, follows a similar protocol in the various existing techniques. In cases with extraction, planning can vary according to the presence or absence of crowding. In the case of crowding, when protrusion of anterior teeth is not desired, tooth extraction is first performed and then the initial canine retraction, that, depending on the technique, can be total or just enough to dissolve the crowding, eliminating the tooth-arch discrepancy. From there on, the wires are changed until insertion of a rectangular wire for retraction. In cases without crowding, tooth extractions can be performed only at the time of retraction of anterior teeth. This protocol has, besides the obvious esthetic purpose, the purpose of avoiding loss of alveolar bone mass, which would occur between the time of extraction and the beginning of the retraction stage. As we all know, few steps prior to the retraction of anterior teeth may take a few months, depending, mainly on the correction of potential deep overbites.

The treatment protocol with the Centrex System 1 (CSl) is similar to a standard treatment. It consists of leveling and alignment of teeth with continuous arches until the retraction rectangular wire. At the end of this stage it is essential that in the lower arch, the curve of Spee has been corrected, enabling the retraction of the upper anterior teeth. Before the beginning
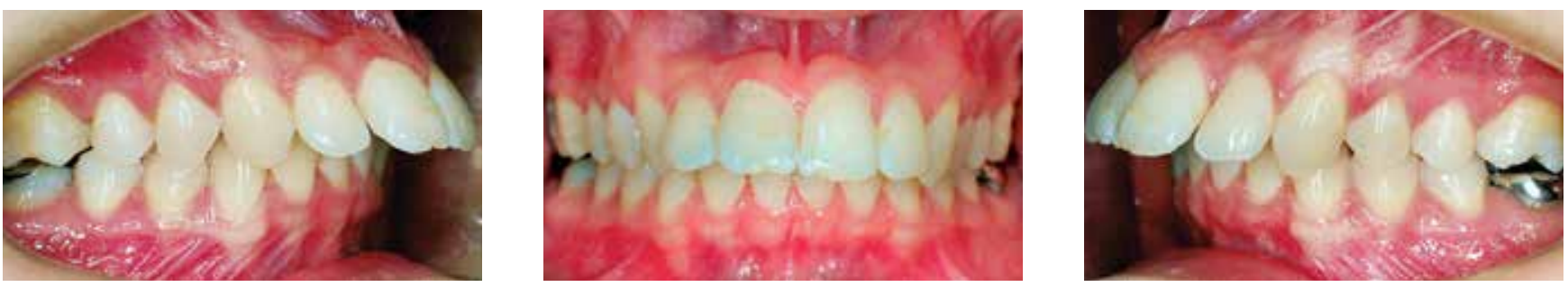

Figure 13 - Upper incisors showing excessive inclination.
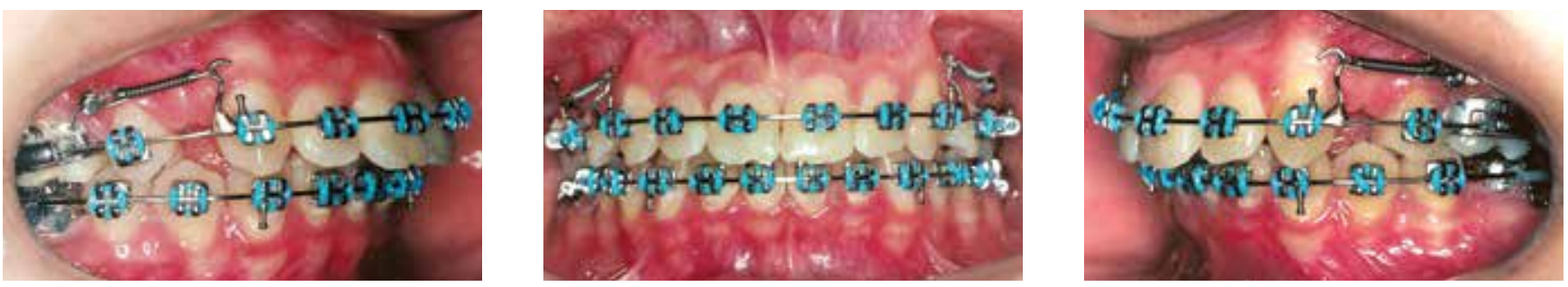

Figure 14 - Stage of upper anterior retraction with welded hooks to rectangular $0.017 \times 0.025$-in wire.
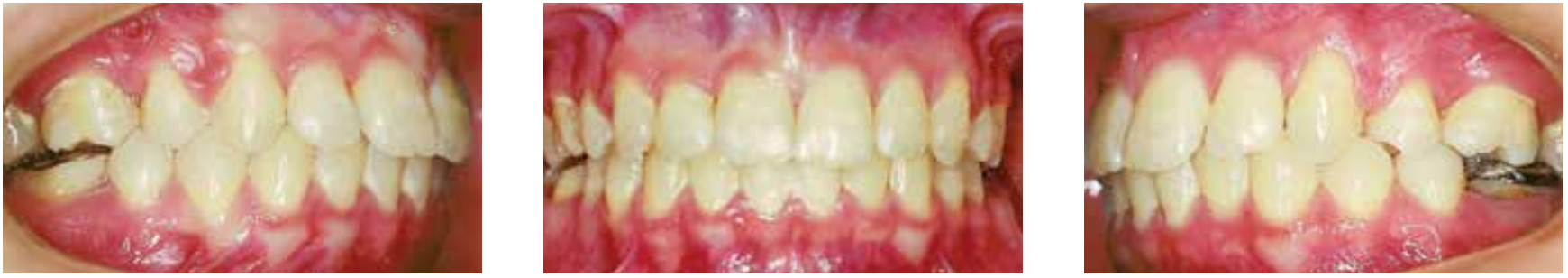

Figure 15 - End of orthodontic treatment. 

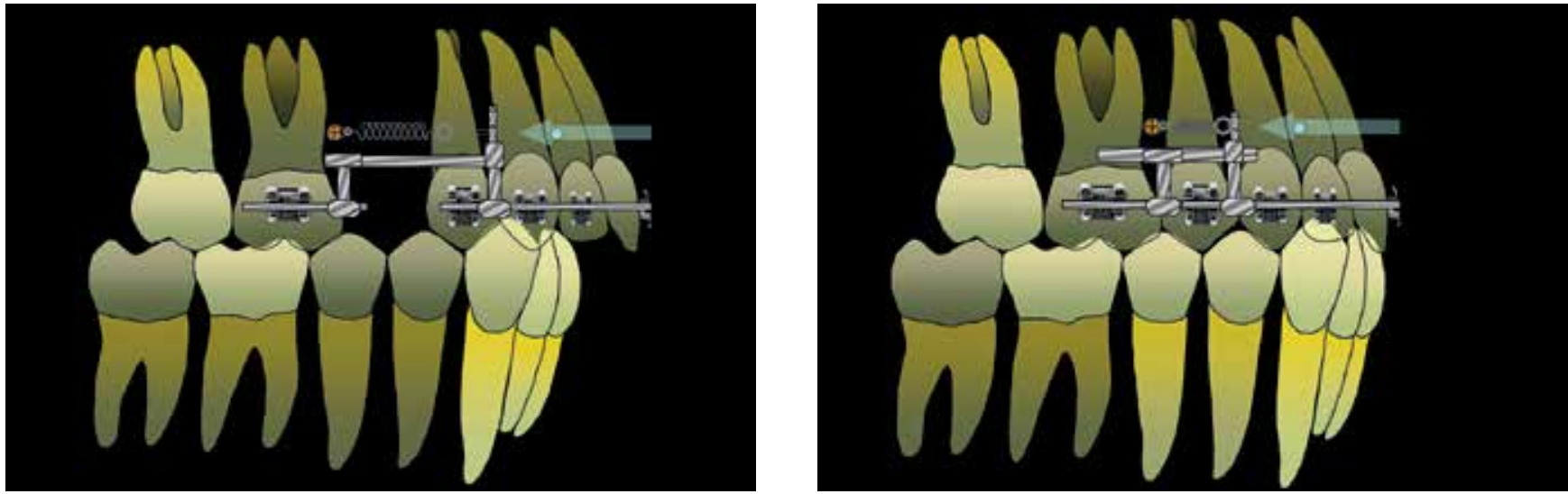

Figure 16 - Retraction of the upper anterior teeth when these are with ideal inclination.
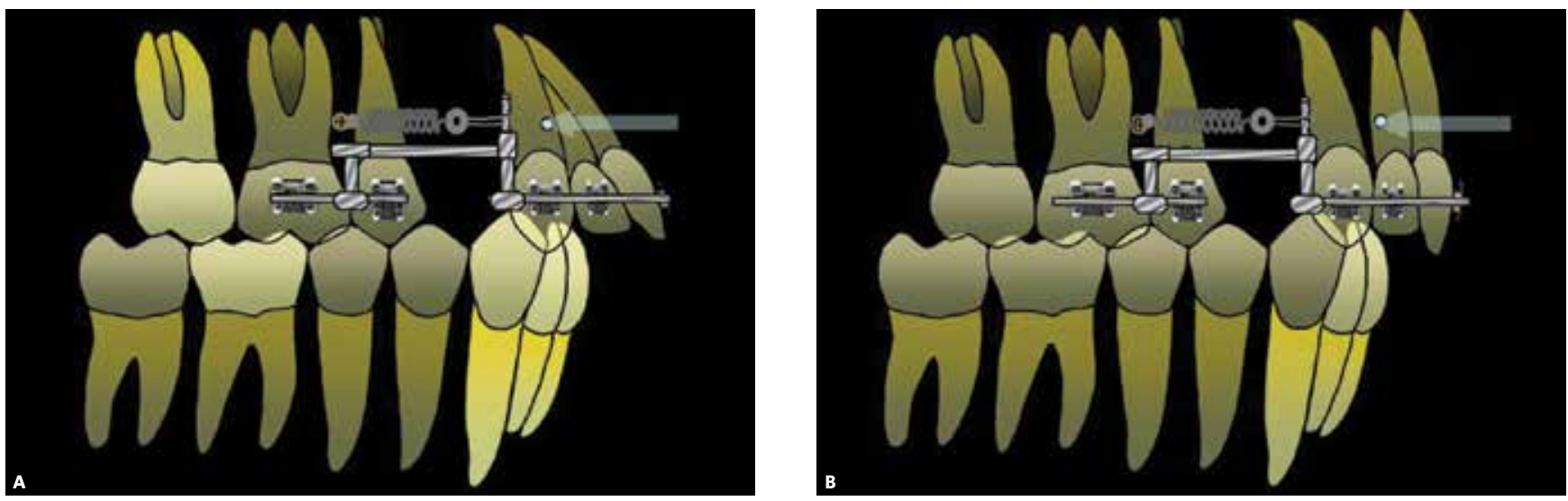

Figure 17 - Anterior teeth with excessive buccal inclination (A). Anterior teeth with insufficient inclination before the retraction (B).

of the next stage, the inclination of these teeth is evaluated to define the need for adjustments.

Here, three situations are possible: The upper incisors can be with the ideal inclination for the case, they can be with excess of buccal inclination (positive) or with a negative inclination. When the upper anterior teeth present an ideal inclination, the goal is to keep them during the retraction phase. To do this, the wire must fill the entire slot for these teeth, thus avoiding the loss of inclination of units to be retracted. The MI are inserted at a height that approaches the center of resistance of the anterior teeth, whose location can be more apical if there is horizontal bone loss in the anterior region. ${ }^{1}$ If the line of force is passing parallel to the occlusal plane and at the center of resistance of teeth that are being moved, the trend is that these teeth will move bodily in a distal direction, without vertical components (Fig 16).

In the case when upper incisors present an excessive buccal inclination at the end of alignment and leveling stage (Fig 17A), treatment occurs in the same way as a treatment with continuous arches. Although inclination correction is possible before the beginning of retraction, this is not the most appropriate approach, since such a correction can be easily achieved during the distal movement of anterior teeth. To do this, the rectangular wire, used to retract, does not fill the whole slot of anterior brackets. For example: a wire measuring $0.018 \times 0.025$-in in a slot $0.022 \times 0.030$-in would allow a slow loss of inclination to the point that we consider ideal. From there, if an additional retraction is required, one can replace the wire by a larger caliber, allowing greater control of incisors.

When the upper anterior teeth present inadequate buccal inclination (Fig 17B), in the same way as conventional mechanics the prior correction of such inclination is required before the beginning of the anterior retraction movement. Facing that situation, 

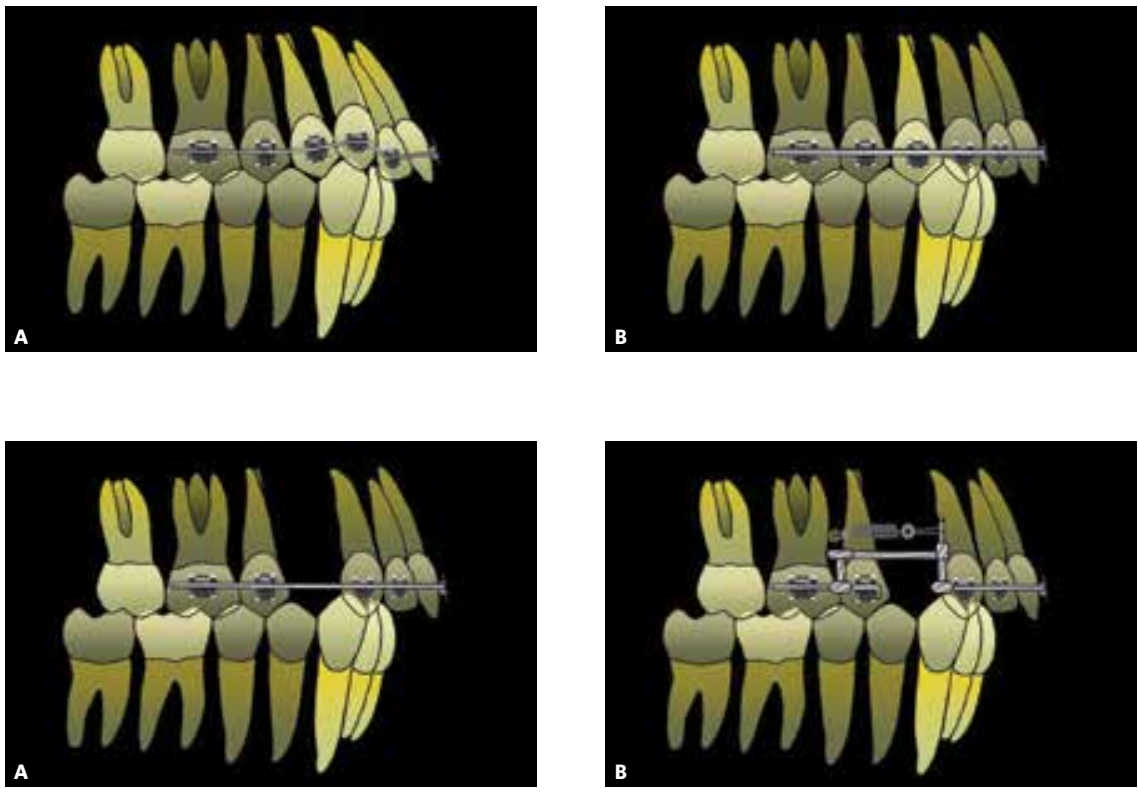

Figure 18 - Summary of Protocol for using CS1: The alignment and leveling of teeth follow by the use of wires of smaller caliber and greater resiliency $(\mathbf{A})$, until reaching the rectangular wires, when all the teeth must be correctly aligned and leveled in the arch (B).

Figure 19 - When the upper teeth are ready to be retracted, extraction of teeth is performed chosen in planning (if they have not been previously extracted) (A). The mini-implants are inserted in the positions shown for the case and the CS1 is installed on the upper arch, which is sectioned, individualizing the anterior and posterior segments (B). the best practice is to continue wire changes up to the rectangular wire of higher caliber compatible with the slot, that will allow full torque expression embedded in pre-adjusted brackets. It is like active buccal crown torque was given to anterior teeth. What can even be necessary if the option is to use standard brackets. After execution of torque correction, the UAR can be initiated with the CSl installation and sectioning of continuous wire, separating the two segments (Figs 18 and 19), which avoids the friction between the wire and brackets during the retraction movement. Below are presented clinical cases treated with the protocol described.

It is an adequate time for a caveat: it is not the intention here to reduce the success of orthodontic mechanics to a simplistic generalization of location of centers of resistance as if they were easily locatable structures. They are not. Several works were conducted attempting to identify its position on different teeth and groups of teeth, without any agreement. ${ }^{18,22}$ In addition, some factors impose additional difficulties to their location, that varies depending, especially on the anatomy of the teeth, the form and amount of bone support and amount of teeth involved in the movement. ${ }^{22}$

With didactic purpose, let's consider, as stated by Smith and Burstone, ${ }^{4,25}$ for teeth with healthy periodontium an approximate location of the center of resistance between the trifurcation of molars. For the block of six anterior teeth we will consider a height of about $10 \mathrm{~mm}$, apical in relation to brackets, and approximately between the roots of the upper lateral incisor and canine. It should be borne in mind, however, that this is merely an estimate and that the exact location setting gives more by way of trial and error and by momentary adjustments during mechanics

\section{Case 4 (Figs 20, 21, 22)}

Female patient looked for orthodontic treatment presenting a bilateral Class II relation, upper anterior and lower posterior crowding in the right side; the upper midline was deviated to the right. In radiographic evaluation, a predominantly horizontal bone loss was detected in the upper anterior region. The treatment plan consisted of the extraction of two first upper premolars, in addition to the second lower pre-molar on the right side. The aim was to lose anchorage in the right side in both the upper and the lower arches, and retract the upper segment for midline correction. When inserting the rectangular wire of $0.019 \times 0.025$-in we initiated the retraction of the left side using the $\mathrm{CS} 1$, which made it possible to establish a higher line of force, which was in line with our planning to maintain the inclination of the upper anterior teeth during retraction.

At the end of treatment, the patient had corrected canine relationship and upper midline, keeping the inclination of the upper incisors. 

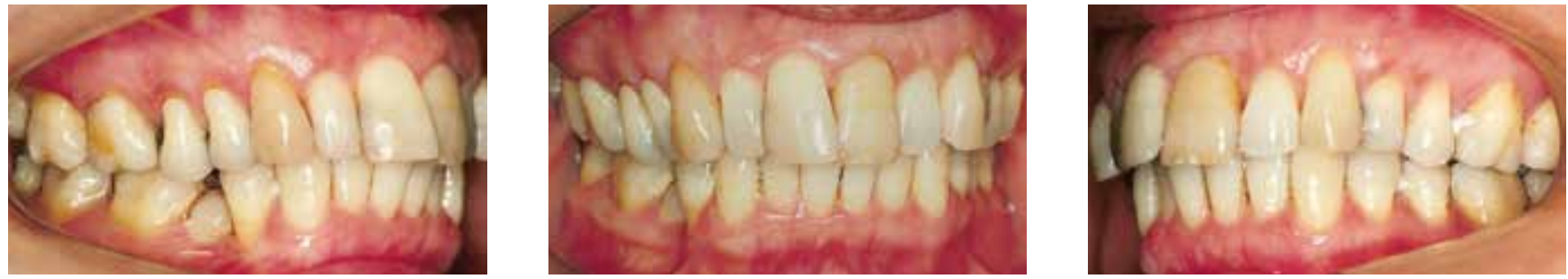

Figure 20 - Bilateral class II malocclusion with crowding in upper anterior and lower posterior right regions.
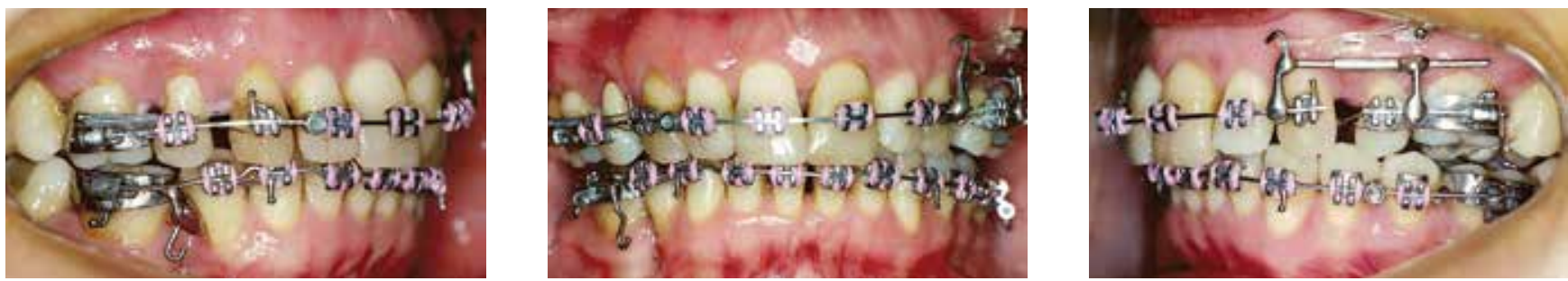

Figure 21 - UAR is a good moment for upper midline correction. In this case, the emphasis is on the left side retraction with CS1 seeking the midline correction.
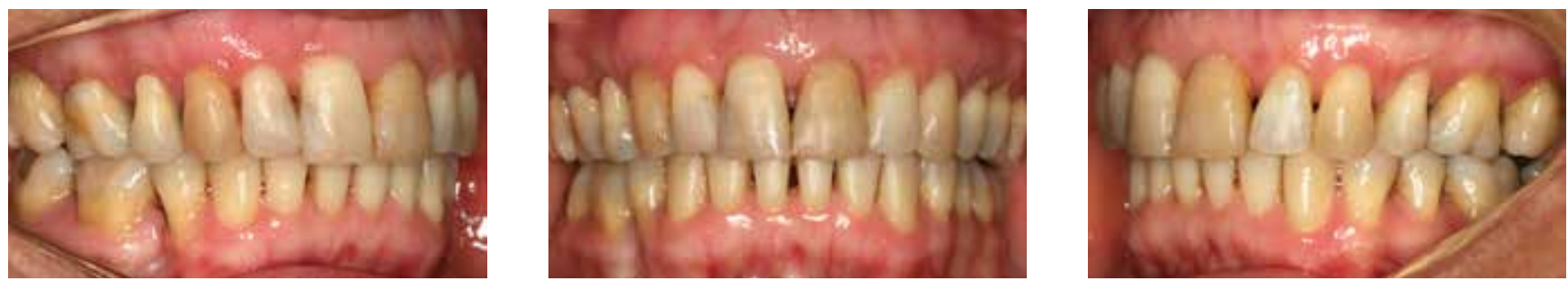

Figure 22 - End of retraction with midline and bilateral canine relationship corrected.

\section{Case 5 (Figs 23 to 26)}

Female patient presented, at the beginning of treatment, a $1 / 2$ Class II canine relation, increased overbite and overjet, that were aggravating due to pathological occlusion. Bone loss in the anterior region of the upper and lower reached the middle apical third. The treatment was performed with the extraction of upper and lower first premolars and insertion of mini-implants buccally positioned between first and second upper molars, at a height of approximately $10 \mathrm{~mm}$ above orthodontic wires. As bone loss produced an apical migration of the center of resistance of anterior upper teeth, the line of force, established during the UAR phase, was set up approximately $10 \mathrm{~mm}$ from the brackets center allowing a small clockwise tendency for the inclination of the anterior block. Once the inclination of the upper anterior teeth was considered acceptable, a rectangular wire $0.021 \times 0.025$-in was inserted to increase inclination control of teeth during the remaining retraction.

At the end of the treatment, overjet, overbite and the exaggerated inclination of incisors were corrected with appropriate control of bone loss. 

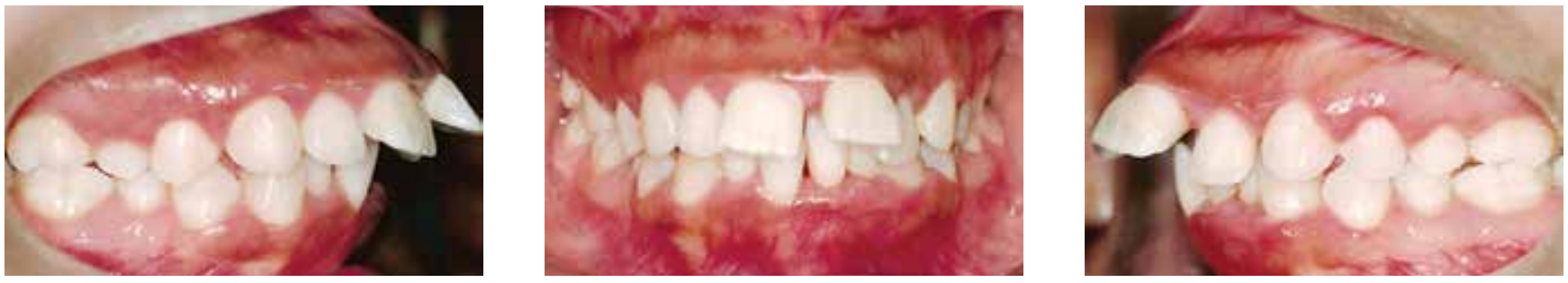

Figure 23 - Beginning of treatment. Opening of anterior teeth exacerbated by occurrence of a pathological occlusion.
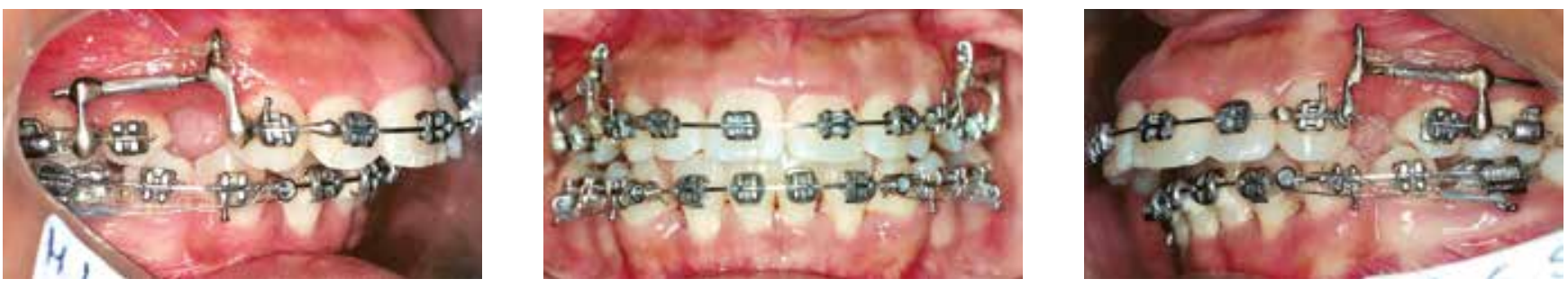

Figure 24 - Active stage of UAR using CS 1.
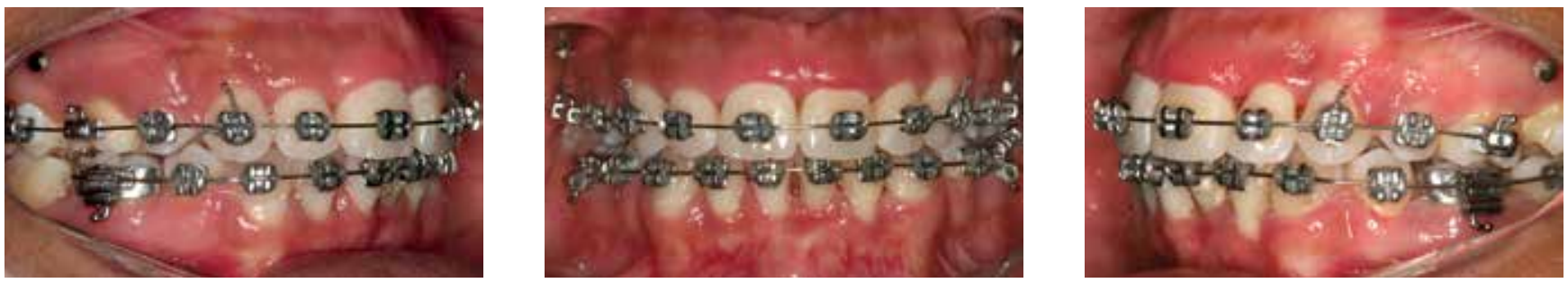

Figure 25 - End of anterior retraction with overjet correction.
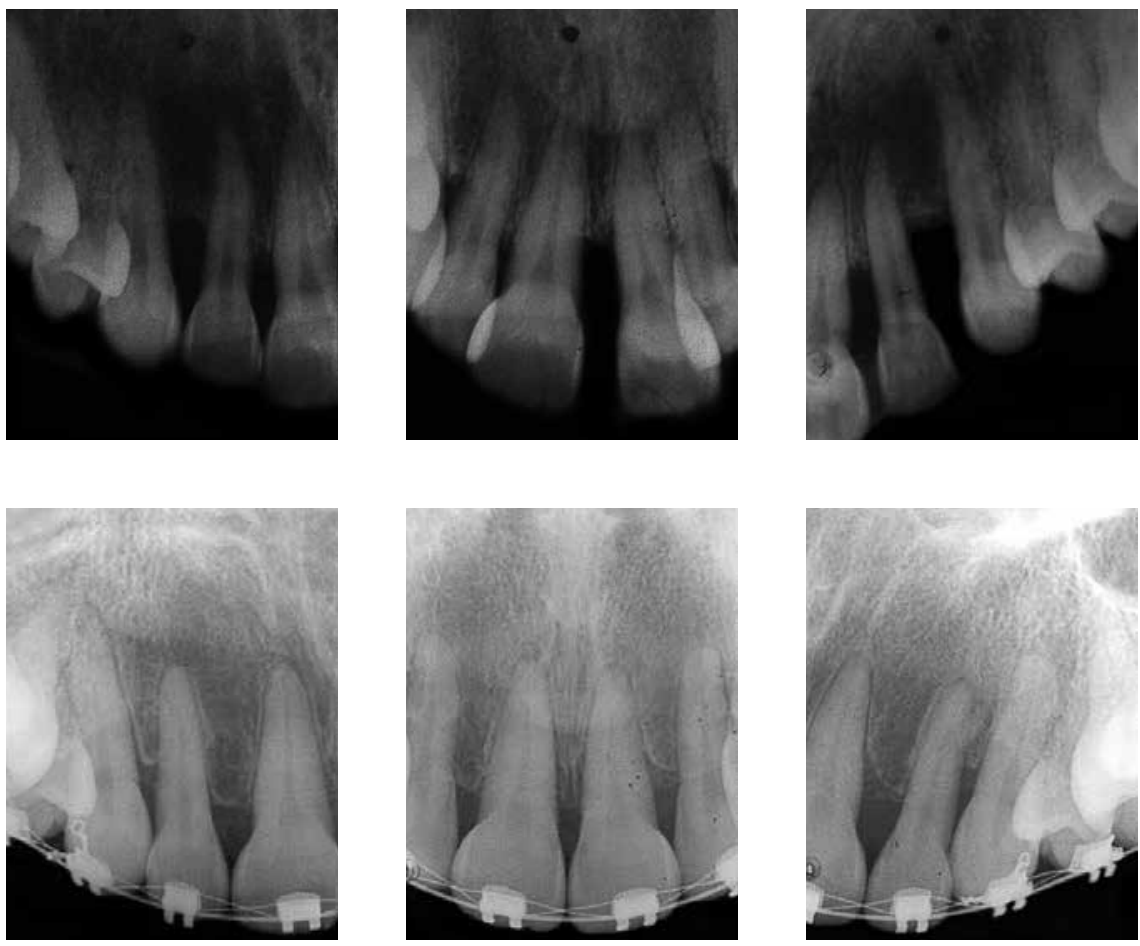

Figure 26 - Radiographic detail of bone loss in the region of upper incisors before treatment and after the retraction stage of upper anterior teeth. The intrusive movement of these teeth led to, on one hand, to apical rounding and, on the other hand, positively, to an improvement in bone insertion levels, providing a beneficial change in the ratio between the resistance arm (root portion inserted into bone) and the lever arm (tooth portion outside of the bone). 


\section{Case 6 (Figs 27, 28, 29)}

The next case discusses the use of CS 1 for correction of upper and lower midlines in a patient previously treated with asymmetrical extractions. The tooth extraction of an upper premolar on the left and another on the right side on the lower arch, produced a complete Class II relation in the right side and a complete Class III in the left side. The two midlines were deviated in opposite directions (Fig 27). Since the goal was to correct midlines without a large inclination of anterior teeth, the mini-implants were inserted at 10 $\mathrm{mm}$ in height, in relation to brackets, and retraction rectangular wires had a caliber of $0.021 \times 0.025$-in. At the end of the treatment the canines and the midlines were corrected. There was, as planned, small change in inclination of the upper and lower teeth.
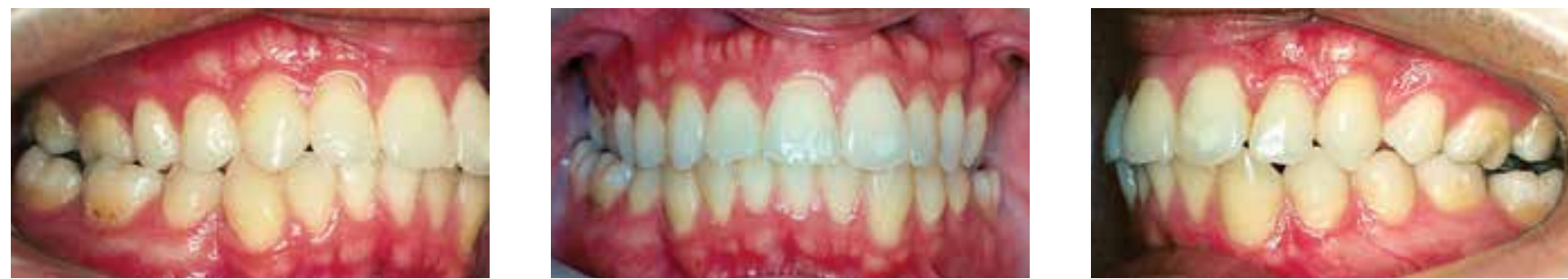

Figure 27 - Complete Class II malocclusion in the right side complete Class III in the left side, resulting from previous orthodontic treatment with asymmetrical extractions.
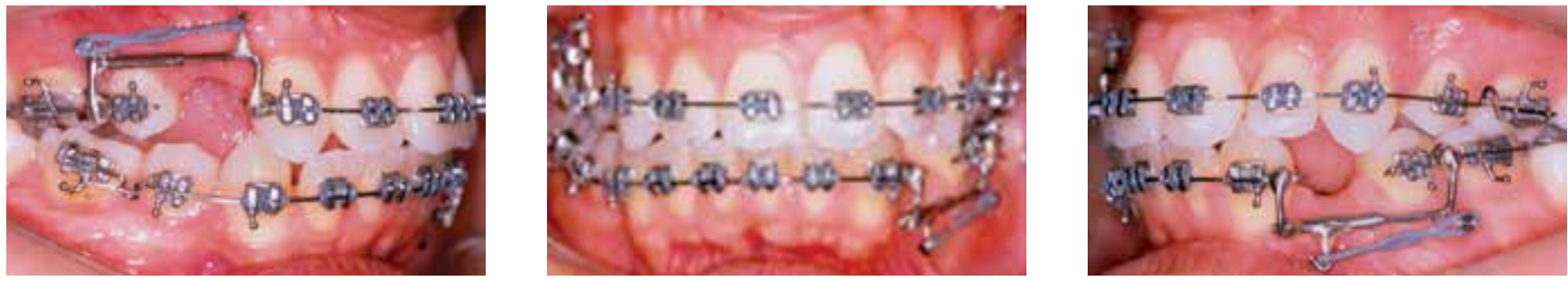

Figure 28 - Asymmetric retraction. In this case, It is important to immobilize the wire on the opposite side to avoid its rotation.
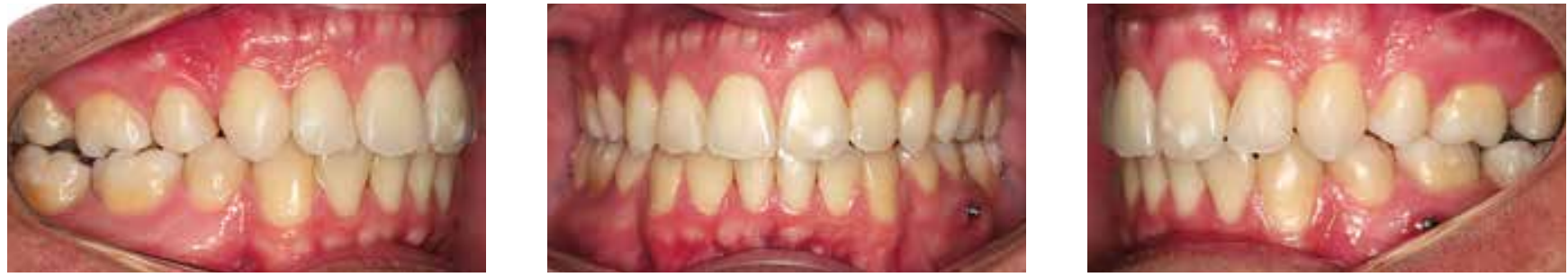

Figure 29 - End of treatment with correction of midlines and canine relation.

\section{Case 7 (Figs 30, 31, 32)}

This case presents the treatment of a bilateral complete Class II. The planning consisted of extraction of teeth 26 and 15. It is important to point out that the choice of tooth 26 was due to the absence of teeth 25 , previously extracted, which imposed an additional difficulty to the case, because of the need for asymmetrical extractions. After leveling and alignment up to the $0.021 \times 0.025$-in rectangular wire in the upper arch, two mini-implants were inserted at a height of $12 \mathrm{~mm}$ in relation to the wire and two CS 1 appliances were used, which have enabled the institution of action line of strength high enough to allow an adequate control of the inclination of upper anterior teeth, which already had a satisfactory buccal lingual position at the onset of treatment. 

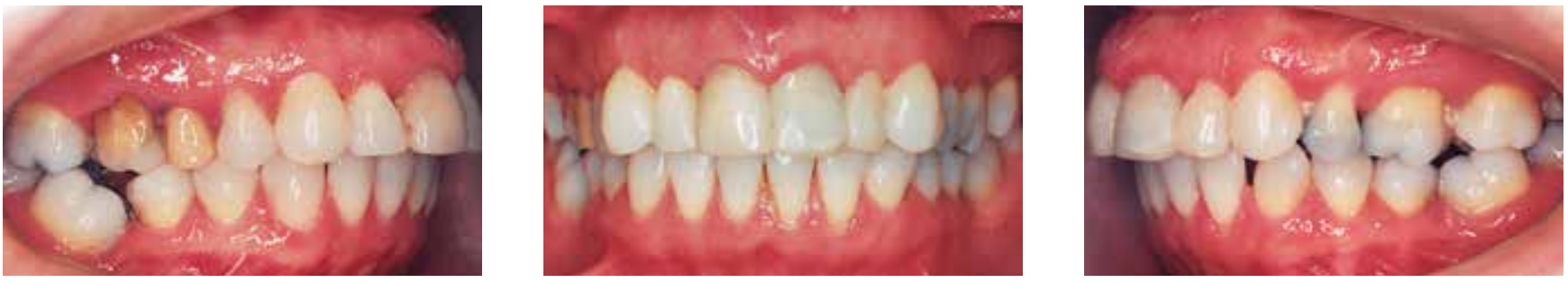

Figure 30 - Class II malocclusion (complete), with upper incisors showing good inclination.
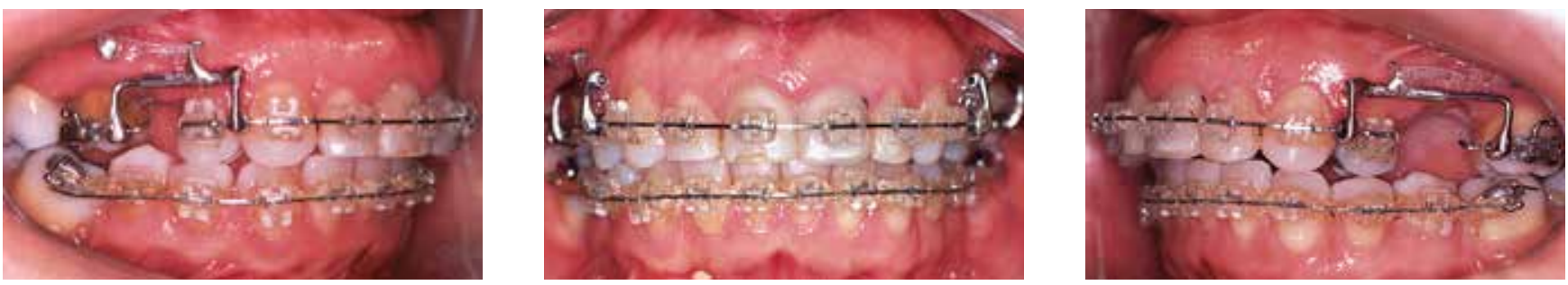

Figure 31 - Bilateral UAR with CS1 appliances.
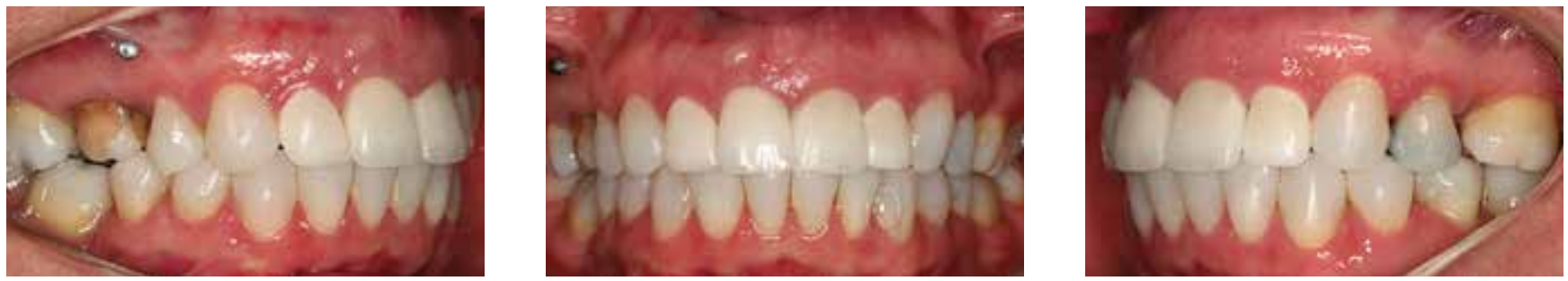

Figure 32 - Bilateral correction of Class II canine relation.

\section{Case 8 (Figs 33, 34, 35)}

Patient 28 years old, presented primary lower crowding and upper incisors protruded in their base, yet with almost ideal inclination. The treatment plan consisted of extracting the first four premolars, with the aim of resolving lower tooth arch discrepancy and incisor protrusion. The MI were inserted in the maxilla bilaterally, at a height of approximately $10 \mathrm{~mm}$ from the wire. In UAR, a $0.021 \times 0.025$-in wire was inserted to maintain the ideal incisor inclination.

\section{DISCUSSION}

The retraction of anterior teeth is apparently just a simple procedure in orthodontic mechanics, however the possible problems during this phase, many of them listed in this work, indicate the contrary. It is a defiant step for the clinician, when one needs to control with enough rigour the undesirable side effects that eventually appear in your course.
One of the most common disadvantages during anterior retraction, with sliding mechanics, is the blocking of movement generated by the friction between the wire and the bracket. ${ }^{5,30}$ For Kusy, ${ }^{15}$ the sliding of a wire inside brackets tends to decrease the mechanical efficiency, demanding an increase in the strength used to compensate for this loss. The magnitude of the friction between bracket and wire varies according to the chemical composition of each one ${ }^{16}$ and the wire caliber. ${ }^{3,13}$ Rectangular wire sectioning within the retraction space, when using CS1, aims to reduce the friction wire/bracket during the distal movement of anterior teeth, which tends to avoid unnecessary loss of mechanical efficiency at that stage, thus allowing the use of smaller magnitude forces, within the physiological adaptation pattern of the periodontium.

Torque control during retraction of six anterior teeth is another topic that can be quite challenging. The incorporation of root lingual torque is often 

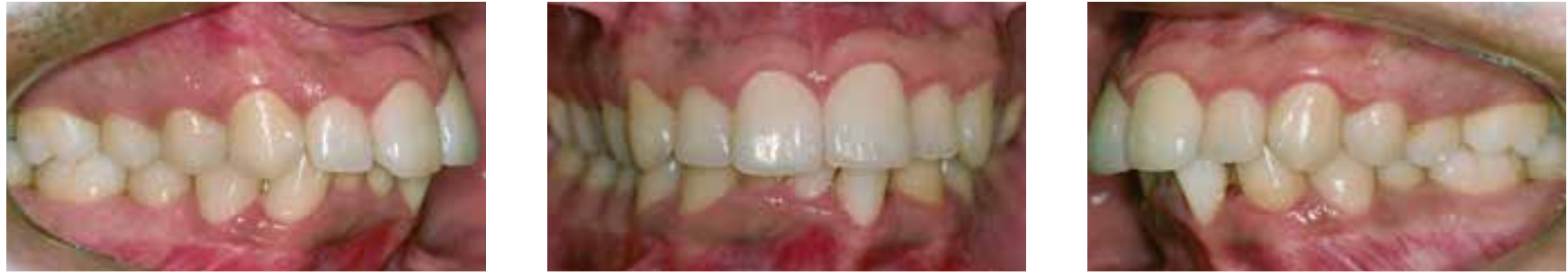

Figure 33 - Class I Malocclusion with lower anterior crowding and protruded upper incisors.
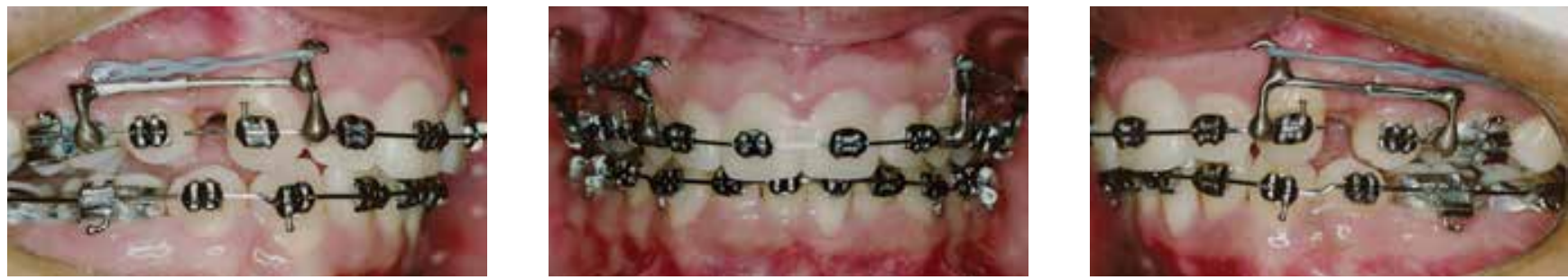

Figure 34 - The upper anterior teeth had good inclination during the retraction phase.
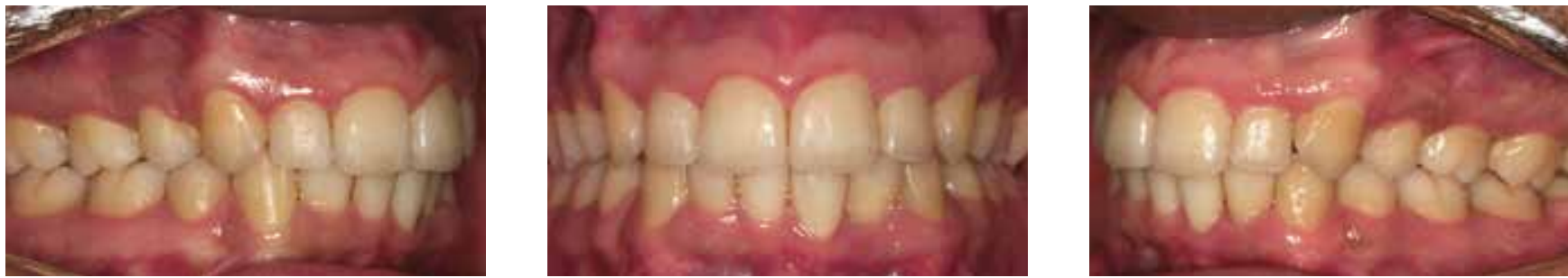

Figure 35 - End of retraction, with maintenance of correct inclinations of upper incisors.

required to avoid excessive retroclination extrusion of the crowns of anterior teeth. ${ }^{19}$ Additionally, a compensatory bend can be incorporated to the wire to compensate the extrusive effect of anterior teeth, ${ }^{20}$ however, this adds friction to the process, which may result in a delay during movement of such teeth.

The occlusal gingival position of MI associated to the height of retraction hooks height in the anterior segment determine the line of force that is generated during the movement of anterior teeth. The possibility of establishing different configurations of line of action towards the center of resistance of these teeth admits various movements without the need of making compensatory torques on incisors. ${ }^{20}$ The CSl allows use of retraction forces in many heights and can generate planned movements of anterior teeth only with the management of the point of origin and force application. Another possibility for manipulation of desired movement takes place by the choice of the caliber of the retraction wire.

It is speculated that the contact of the root apex with the buccal or lingual cortical can be one of the main factors of root resorption during orthodontic treatment. ${ }^{\text {ll }}$ Such contacts are often generated during uncontrolled inclination movements of incisor teeth in retractions or buccal movement of such teeth. Alveoli with reduced thickness, as is often found in patients with increased facial height, can increase the risk of root resorption. ${ }^{10}$

It is not entirely clear if the tooth movement in situations of retraction of anterior teeth raises a complete alveolar remodeling around the moved teeth. Edwards ${ }^{9}$ believes that such a remodeling occurs in the segment between the alveolar margin and the middle third of the root, not occurring to the apical third level. For him, if the applied forces are within the limits of tissue tolerance, the bone 
remodeling moves the alveolus with the tooth. Some authors share the same hypothesis, ${ }^{8,20}$ while others argue that any tooth movement that forces incisors against the cortical bone can cause sequelae, such as root and cortical bone resorption, in addition to the tooth exposure. ${ }^{23,29}$ The proposal of $\mathrm{CSl}$ is that, through the rigorous control of orthodontic movement, it can decrease the risk of pressing the apical region against the cortical bone, thereby reducing the chances of root resorption during the retraction stage.

It is essential to assess the magnitude of the facial changes induced by tooth retraction. Although this might be welcome in some individuals presenting, for example, lip protrusion as the first clinical case presented in this text.

\section{CONCLUSIONS}

This work presented a treatment possibility with a device that approximates the line of action of forces to the center of resistance of the teeth that are being moved, thereby reducing some of the harmful side effects during anterior retraction.

The Orthodontist having at his reach a series of different orthodontic techniques and therapeutic resources, can choose the best option for closing spaces originated from extractions in the upper arch. The proposal of CSl is the use of biomechanical features based on fundamental knowledge of Orthodontics. The possibility of placing MI in various positions gives us the therapeutic versatility needed to choose the type of desired movement through manipulation of the line of action of forces.

\section{REFERENCES}

1. Bantleon $\mathrm{H}$. Modified lingual lever arm technique: biomechanical considerations. In: Nanda R. Biomechanics in clinical orthodontics. Philadelfia: WB Saunders; 1977. p. 5-241.

2. Bennett JC, McLaughlin RP. O tratamento ortodôntico da dentição com o aparelho préajustado. São Paulo: Artes Médicas; 1998.

3. Braun S, Bluestein M, Moore BK, Benson G. Friction in perspective. Am J Orthod Dentofacial Orthop. 1999 Jun;15(6):619-27.

4. Burstone CJ, Pryputniewicz RJ. Holographic determination of centers of rotation. Am J Orthod. 1980 Apr;77(4):396-409.

5. Cacciafesta V, Sfondrini MF, Ricciardi A, Scribante A, Klersy C, Auricchio F. Evaluation of friction of stainless steel and esthetic self-ligating brackets in various bracketarchwire combinations. Am J Orthod Dentofacial Orthop. 2003 Oct;124(4):395-402.

6. Capelozza Filho L, Silva Filho OG, Ozawa TO, Cavassan AO. Individualização de braquetes na técnica Straight-Wire: revisão de conceitos e sugestões de indicações para uso. Rev Dental Press Ortodon Ortop Facial. 1999 Jul-Ago;4(4):87-106.

7. Chan E, Darendeliler MA. Physical properties of root cementum: Part 5. Volumetric analysis of root resorption craters after application of light and heavy orthodontic forces Am J Orthod Dentofacial Orthop. 2005 Feb;127(2):186-95.

8. De Angelis V. Observations on the response of alveolar bone to orthodontic force. Am J Orthod. 1970 Sep:58(3):284-94.

9. Edwards JG. A study of the anterior portion of the palate as it relates to orthodontic therapy. Am J Orthod. 1976 Mar;69(3):249-73.

10. Handelman CS. The anterior alveolus: its importance in limiting orthodontic treatment and its influence on the occurrence of iatrogenic sequelae. Angle Orthod. 1996;66(2):95109; discussion 109-10.

11. Horiuchi A, Hotokezaka H, Kobayashi K. Correlation between cortical plate proximity and apical root resorption. Am J Orthod Dentofacial Orthop. 1998 Sep;114(3):311-8.

12. Kanomi R. Miniimplant for orthodontic anchorage. J Clin Orthod. 1997 Nov;31(11):763-7.

13. Kapila S, Angolkar PV, Duncanson MG Jr, Nanda RS. Evaluation of friction between edgewise stainless steel brackets and orthodontic wires of four alloys. Am J Orthod Dentofacial Orthop. 1990 Aug;98(2):117-26.

14. Kim SH, Choi YS, Hwang EH, Chung KR, Kook YA, Nelson G. Surgical positioning of orthodontic mini-implants with guides fabricated on models replicated with cone beam computed tomography. Am J Orthod Dentofacial Orthop. 2007 Apr;131(4 Suppl):S82-9.

15. Kusy RP, Whitley JQ. O atrito nas diferentes configurações de fio-bracket e materiais. In: Sadowsky PL. Atualidades em Ortodontia. São Paulo: Premier; 2002. p. 177-88.
16. Loftus BP, Artun J, Nicholls Jl, Alonzo TA, Stoner JA. Evaluation of friction during sliding tooth movement in various bracket-arch wire combinations. Am J Orthod Dentofacial Orthop. 1999 Sep;116(3):336-45.

17. Lupi JE, Handelman CS, Sadowsky C. Prevalence and severity of apical root resorption and alveolar bone loss in orthodontically treated adults. Am J Orthod Dentofacial Orthop. 1996 Jan;109(1):28-37.

18. Matsui S, Caputo AA, Chaconas SJ, Kiyomura H. Center of resistance of anterior arch segment. Am J Orthod Dentofacial Orthop. 2000 Aug;118(2):171-8.

19. Meireles JKS, Ursi W. Centrex: uma proposta de sistema de forças ortodônticas para atuação no centro de resistência. Rev Dental Press Ortodon Ortop Facial. 2007 NovDez;12(6):38-47.

20. Park HS, Kwon TG. Sliding mechanics with microscrew implant anchorage. Angle Orthod. 2004 Oct; 74(5):703-10.

21. Park YC, Choi YJ, Choi NC, Lee JS. Esthetic segmental retraction of maxillary anterior teeth with palatal appliance and orthodontic mini-implants. Am J Orthod Dentofacial Orthop. 2007 Apr;131(4):537-44.

22. Pedersen $\mathrm{E}$, Andersen $\mathrm{K}$, Melsen $\mathrm{B}$. Tooth displacement analyzed on human autopsy material by means of a strain gauge technique. Eur J Orthod. 1991 Feb;13(1):65-74.

23. Sarikaya S, Haydar B, Cigğer S, Ariyürek M. Changes in alveolar bone thickness due to retraction of anterior teeth. Am J Orthod Dentofacial Orthop. 2002 Jul;122(1):15-26.

24. Silva Filho OG, Meireles JKS, Ferrari Junior FM. Reabsorção radicular após o tratamento ortodôntico: revisão de literatura Parte 1. Ortododontia. 1997 Jan-Abr;30(1):52-67.

25. Smith RJ, Burstone CJ. Mechanics of tooth movement. Am J Orthod Dentofacial Orthop. 1984 Apr;85(4):294-307

26. Stoner JE, Mazdyasna S. Gingival recession in the lower incisor region of 15 year old subjects. J Periodontol. 1980 Feb;51(2):74-6.

27. Sung JH, Kyung HM, Bae SM, Park HS, Know OW, McNamara Junior JA. Mini implantes. Nova Odessa: Napoleão; 2007. p. 45-68.

28. Wehrbein H, Merz BR, Diedrich P, Glatzmaier J. The use of palatal implants for orthodontic anchorage. Design and clinical application of the orthosystem. Clin Oral Implants Res. 1996 Dec;7(4):410-6.

29. Wehrbein H, Fuhrmann RA, Diedrich PR. Periodontal conditions after facial root tipping and palatal root torque of incisors. Am J Orthod Dentofacial Orthop. 1994 Nov;106(5):455-62.

30. Ziegler $P$, Ingervall $B$. A clinical study of maxillary canine retraction with a retraction spring and with sliding mechanics. Am J Orthod Dentofacial Orthop. 1989 Feb;95(2):99-106. 